\title{
Satisfaction with Aspects of Daily Life: Japan 2013
}

\author{
Takashi Inoguchi \\ University of Tokyo / University of Niigata Prefecture \\ Japan
}

\begin{abstract}
How satisfied or dissatisfied people are with aspects of daily life such as housing, income, health, family, food, human relations, and work provides vital information about them. On the basis of a nation-wide random sample survey in Japan in October 2013, this article analyzes Japanese citizens' daily life satisfaction in a snapshot. The big picture of Japanese daily life is that they are more or less satisfied with their daily life, although income, work, and housing register lower levels of satisfaction in comparison to other aspects like food, family, human relations, and health. Their satisfaction is focused on food, family, and human relations.
\end{abstract}

Key words: Quality of life, aspects of daily life, satisfaction, Japan.

All correspondence concerning this article should be addressed to Takashi Inoguchi, University of Niigata Prefecture, 471, Ebigase, Higashi-ku, Niigata City, Niigata, Japan 950-8680.Email: inoguchi@ioc.u-tokyo.ac.jp. 
Popular satisfaction with aspects of daily life such as housing, income, health, family, food, human relations, and jobs is examined with a nation-wide random sample survey carried out in October 2013.

The Japanese survey asks the following question.

Q Please tell me how satisfied you are with following aspects of your life (choose one for each)

\begin{tabular}{|l|l|c|c|c|c|}
\hline & & Satisfied & $\begin{array}{l}\text { Somewhat } \\
\text { satisfied }\end{array}$ & $\begin{array}{l}\text { Somewhat } \\
\text { dissatisfied }\end{array}$ & Dissatisfied \\
\hline a & housing & 1 & 2 & 3 & 4 \\
\hline b & Household income & 1 & 2 & 3 & 4 \\
\hline c & Health & 1 & 2 & 3 & 4 \\
\hline d & Family life & 1 & 2 & 3 & 4 \\
\hline e & Food & 1 & 2 & 3 & 4 \\
\hline f & Human relations & 1 & 2 & 3 & 4 \\
\hline g & Job & 1 & 2 & 3 & 4 \\
\hline
\end{tabular}

Quota sampling within randomly selected households was carried out by the Nihon Research Center. The primary sampling units were selected through a stratified random sampling procedure where households were selected using a residential map database. Individuals were interviewed based on a proportional quota in the population. Interviewing was carried out nationwide by interviewers visiting 1,200 interviewees, aged 15-79, and door to door.

Previous studies (Kamo, 1998; Kasago, 2007; Piccolo, Judge, Takahashi, Watanabe, \& Locke, 2005) carefully examined Japanese daily life satisfaction. However, the focus of their articles was substantially different from this article's, and the contexts in which surveys were carried out were different. This article focuses on a broad nationwide picture of Japanese citizens' satisfaction with aspects of daily life in the cross-national framework of 12 society surveys (Inoguchi et al., 2014). 
Two major weaknesses of this cross-national survey must be pointed out. First, the Japanese survey was carried out gratis by the Nihon Research Center. Only one question about satisfaction with each aspect of daily life was asked to interviewees along with a number of associated demographic questions. One cannot go very far with regards to statistical analysis. Second, the 12 societies' surveys differ substantially from each other in terms of sampling methods and interviewing modes due to differences in the financial resources and analytical personnel available to each society's survey team. Otherwise, cross-national comparative multivariate analysis would have been adopted. A snapshot comparison in the form of graphs was carried out in Inoguchi et al. (2014).

The big picture is that Japanese citizens are more or less satisfied with most aspects of daily life although income, work, and housing register lower levels of satisfaction in comparison to other aspects like food, family, human relations, and health.

Figure 1

Satisfaction with Seven Aspects of daily life

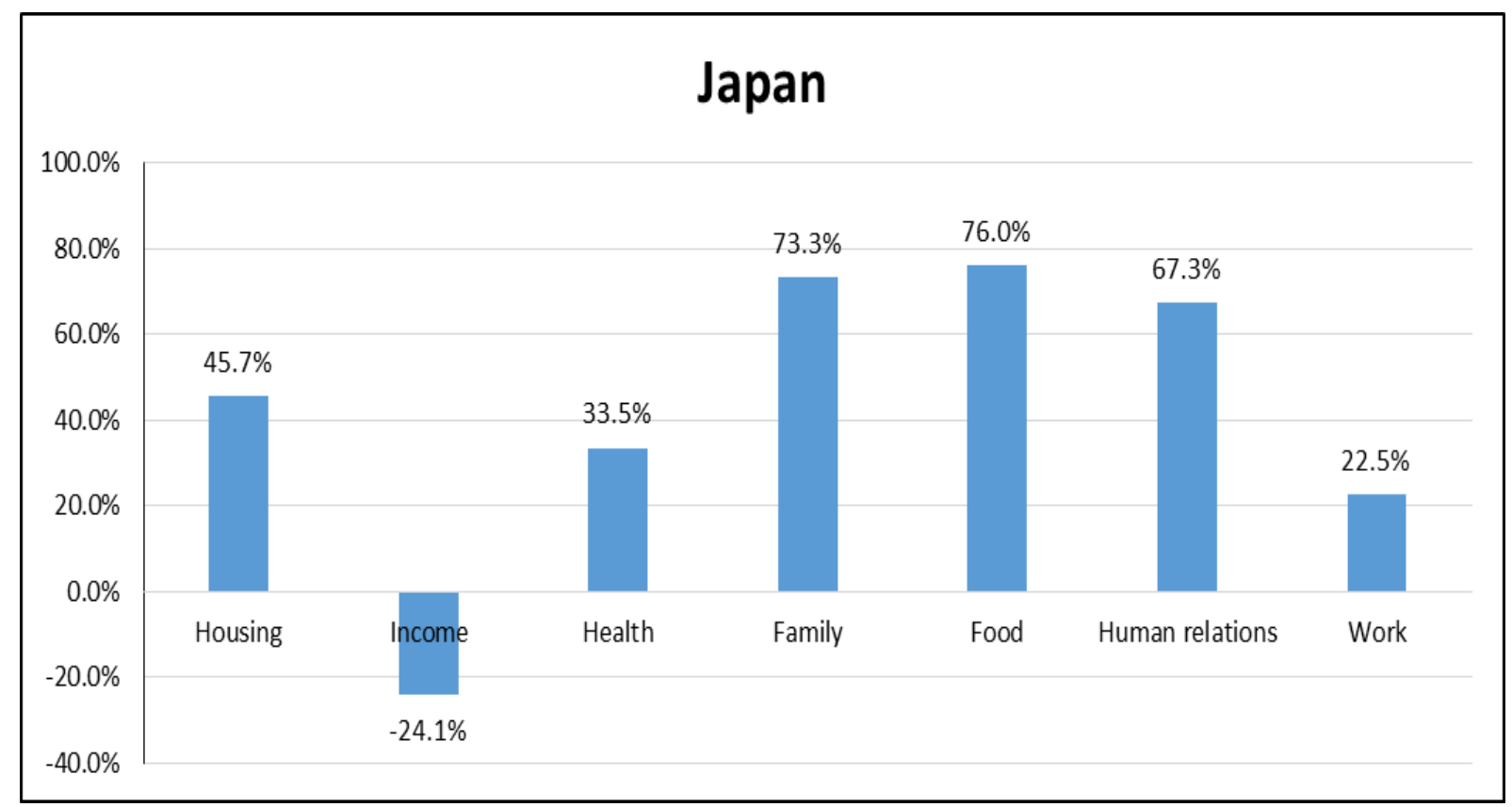

* Metrics in Figure 1 are constructed as follows:

The percentage of those satisfied and somewhat satisfied minus the percentage of those somewhat dissatisfied and dissatisfied with regards to a) housing, b) household income, c) health, d) family life, e) food, f) human relations, and g) job. 
Noteworthy in the context of the Japanese economy is the lower level of satisfaction with work and with income. Employment situations are not excellent for employees because irregular employment has been rising and income may be slowly deteriorating given the mild rise of inflation without an accompanying wage hike. Satisfaction with housing, health, and human relations are interesting in that they require a vast investment of efforts. Housing requires a lot of money to acquire; health requires daily attention and care; work requires daily work. During hard times, work, income, and housing satisfaction come less easily. Health and human relations lie in between food and family on the one hand and work, income and housing on the other. Food and family are aspects of daily life which are enjoyed with intimates. Income and housing are aspects of daily life which can be enjoyed only with good investment. Food and family provide satisfaction from intimacy, and work and income provide satisfaction from investment. It is not that the former does not need investment while the latter does not provide you intimacy. Both need commitment; then some satisfaction ensues. On the whole Japanese citizens' satisfaction with aspects of daily life are high, as seen from the level of satisfaction in October 2013.

\section{References}

Inoguchi, T., Basanez, M., Kubota, Y., Cho, S. K., Kheokao, J., Krirkgulthorn, T., Chung, R. ... Gilani, I. S. (2014). Daily life satisfaction in Asia: A cross-national survey in twelve societies, Asian Journal of Public Opinion Research, 1(3), 153-202. doi: http://dx.doi.org/10.15206/ajpor.2014.1.3.153

Kamo Y. (1998). Sociological determinants of life satisfaction in Japan: The roles of gender, family and work. International Journal of Japanese Sociology, 7, 127-153.

Kasago, T. (2006). Rethinking of economic growth and life satisfaction in post-WWII Japan: A fresh approach. Social Indicators Research, 81, 79-102.

Piccolo, R. F., Joudge, T. A., Takahashi, K., Watanabe, N., \& Locke. E. A. (2005). Core selfevaluations in Japan: Relative effects on job satisfaction, life satisfaction, and happiness. Journal of Organizational Behavior, 26, 965-984. 


\section{Biographical Note}

Takashi Inoguchi is Professor Emeritus, University of Tokyo and President, University of Niigata Prefecture. He is also former Assistant Secretary General of the United Nations assigned to The United Nations University Headquarters. He has B.A. and M.A. degrees from University of Tokyo and a Ph.D. from MIT. He has published numerous books and articles on a broad range of subjects. For the last decade he has executed large scale random sampled nation-wide surveys in all the Asian countries and societies (i.e., in East, Southeast, South and Central Asia, except for the Democratic People's Republic of Korea and Timor Leste) focusing on quality of life and well-being with 60 thousand respondents and 6 million observations. From this AsiaBarometer project he has published with co-author Seiji Fujii, The Quality of Life in Asia: A Comparison of Quality of Life in 29 Asian Countries and Societies (Springer, 2012). With Doh Chull Shin, coedited The Quality of Life in Asia (Springer 2010), coedited with Miguel Basanez et al., Values and Lifestyle in Urban Asia (SigloXXI Editores, 2005), and another three volumes of the AsiaBarometer (Akashi Shoten, 2001, 2008, 2009). On Japan and international affairs, he has published, among others, The Political Economy of Japan (Stanford University Press, 1988, coedited with Daniel Okimoto), American Democracy Promotion (Oxford University Press, 2000, coedited with Michael Cox and G. John Ikenberry), Japanese Politics Today (Palgrave Macmillan, 2011), and The U.S.-Japan Security Alliance (Palgrave Macmillan, 2011). Dr. Inoguchi is a member of the Science Council of Japan, Founding Editor of Japanese Journal of Political Science (Cambridge University Press) and Journal of International Relations of the Asia Pacific (Oxford University Press). Of late, he is editor of Asian Journal of Political Opinion Research (open access journal). He also is Director of the AsiaBarometer Project and is Chairman of the Asian Consortium for Political Research. He won the ISQOLS (International Society for Quality of Life Studies) Research Fellow Award in 2014. Based on Google Scholar Impact Indices, his total citations count (up to November 11, 2013) is 2,164; his h-index is 24, and his i10 index is 59.

He can be reached at: University of Niigata Prefecture, 471, Ebigase, Higashi-ku, Niigata City, Niigata, Japan 950-8680 or by email at: inoguchi@ioc.u-tokyo.ac.jp.

Date of the submission: 2014-09-09

Date of the review result: 2014-10-05

Date of the decision: 2014-10-29 